\title{
NOTÍCIAS E COMENTÁRIOS
}

\section{CORREÇÕES / CORRECTIONS}

Degeneração Walleriana de origem vascular em ressonância magnética de paciente com paralisia supranuclear prog ressiva provável: fator etiológico ou associação fortuita? PRA Rosa, CR Ferreira. Arq Neuropsiquiatr 2005;63:878-880

A Figura 4 deste artigo não foi publicada. Em seu lugar, repetiu-se a Figura 3. Abaixo consta a Figura 4 e sua legenda. Com a equipe do periódico, o Editor pede aos Autores do artigo que relevem este lamentável engano.

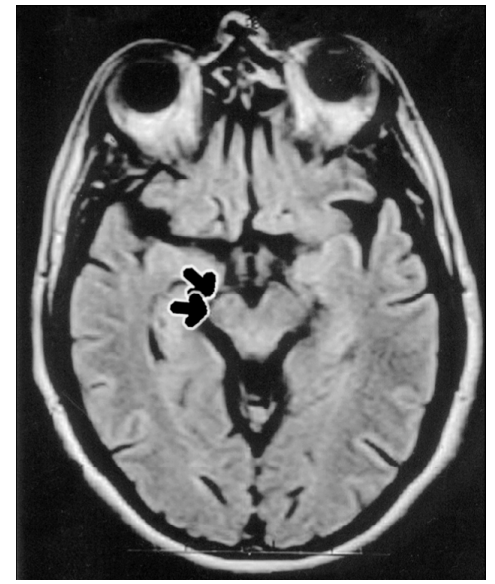

Fig 4. Corte axial na seqüência ponderada $\mathrm{T} 1$, evidenciando redução do pedúnculo cerebral à direita (setas).

Retropulsion and vertigo in the Chiari malformation: case report. JAG Silva, MMA Holanda, $C B$ Pereira, MD Leiros, AF Araújo, E Bandeira. A rqNeuropsiquiatr 2005;63:870-873

José Alberto Gonçalves da Silva, primeiro autor deste artigo solicita a publicação do seguinte: "The authors correct the type II description of the Chiari malformation as follows: "The Type II showed downward displacement of portions of the cerebellum (1891), and portions of the inferior vermis (1895), pons, medulla oblonga and, at least, a part of lengthened fourth ventricle, which reached the disc $\mathrm{C} 4-\mathrm{C5}$, into the enlarged cervical spinal canal".

Neuroproteção no acidente vascular cerebral: opinião nacional. GR Freitas, JK Noujaim, SR Haus sen, FI Yamamoto, EM Novak, RJ Gagliardi e Sociedade Brasileira de Doenças Cerebrovasculares. Arq Neuropsiquiatr 2005;63:889-891

O primeiro autor esclarece que Eli Faria Evaristo é membro da Sociedade Brasileira de Doenças Cerebrovasculares. Por um lapso dele, o nome desse memb ro não consta do rodapé da primeira página do artigo.
FUNDACIÓ VIDAL i BARRAQUER (FVB), INSTITUT UNIVERSITARI de SALUT MENTAL: PROGRAMA 20052006 MASTERS i POSTGRAUS. A partir do segundo semestrede 2005 em Barcelona, Espanha realizamse os cursos de Mestrado em Psicopatologia Clínica e de Psicoterapia Clínica e os cursos de pós-graduação de Psicopatologia Clínica, Psicoterapia e Saúde Mental. A duração dos cursos de mestrado é cerca de dois anos e a dos de pós-graduação, cerca de um ano. A coordenação e o patrocínio dessa atividade são da Universitat Ramon Llul, com o suporte do Cooegi Oficial de Psicòlogos de Catalunya (COPC). Informes: Departa ment de Docencia, FVB (www.fvb.es), C/ Sant Gervasi de Cassoles 88-90, 08022 Barcelona (Fax 93211 0032; e-mail docencia@fvb.es).

XIII SYMPOSIUM INTERNACIONAL SOBRE ACTUALIZACIONES Y CONTROVERSIAS EN PSIQUIATRÍA: TEMAS Y RETOS EN LA PSICOPATOLOGÍA ACTUAL. Em 30 e 31 março 2006 na cidade de Barcelona (Hotel Fira Palace), participando da organização os Professores Luis Sánchez Planell e Julio Vallejo. Temas: comorbidade psiquátrica, personalidade e psicopatologia, despersonalização, humor depressivo, sintomas afetivos subliminares, condutas autolesivas, alucinações auditivas, depressão e esquizofrenia. Informes e inscrições: na Secretaria Técnica: Grupo Geyseco, Marina 27 Bajos (Villa Olimpica), 08005 Barcelona, Espanha (www.gnupogeyseco.com/controversias.htn) ou por fax (932 217 005) ou e-mail (controversias@ geyseco.com).

XXII CONGRESSO BRASILEIRO DE NEUROLOGIA. De 19 a 23 agosto 2006 na cidade do Recife (Centro de Convenções de Pernambuco) realiza-se este congresso, o evento magno da Academia Brasileira de Neu rologia (ABN). Os colegas Gilson Edmar Gonçalves e Silva (Presidente), Maria Lúcia Brito Ferreira (Secretária) e Maria Eunice de $V$ Coelho (Te so u reira) preparam o inovador congresso. Informes: na $A B N$ ou com os oficiais do congresso mencionados acima ou no www.neuro2006.com.br

JOINT WORLD CONGRESS OF STROKE. De $\mathbf{2 6}$ a 29 outubro 2006 em Capetown, África do Sul. Este evento é preparado em conjunto pela International St rcke Society, Mediterranean Stroke Societey, Southe rn Africa Stroke Foundation. Tema central: AVC. Para informes preliminares, consultar: www.kenes. com/st roke2006 ou consultar Kenes International, 17 rue du Cendrier, CH-1211 Geneva1, Switzerland (Fax 4122732 2850; e-mail stroke2006@kenes.com). 